\title{
Peroxy radical detection for airborne atmospheric measurements using absorption spectroscopy of $\mathrm{NO}_{2}$
}

\author{
M. Horstjann, M. D. Andrés Hernández, V. Nenakhov, A. Chrobry, and J. P. Burrows \\ Institute of Environmental Physics, University of Bremen (IUP-UB), Otto-Hahn-Allee 1, 28359 Bremen, Germany \\ Correspondence to: M. Horstjann (markus.horstjann@iup.physik.uni-bremen.de) \\ Received: 18 September 2013 - Published in Atmos. Meas. Tech. Discuss.: 8 November 2013 \\ Revised: 3 March 2014 - Accepted: 14 March 2014 - Published: 13 May 2014
}

\begin{abstract}
Development of an airborne instrument for the determination of peroxy radicals (PeRCEAS - peroxy radical chemical enhancement and absorption spectroscopy) is reported. Ambient peroxy radicals $\left(\mathrm{HO}_{2}\right.$ and $\mathrm{RO}_{2}, \mathrm{R}$ being an organic chain) are converted to $\mathrm{NO}_{2}$ in a reactor using a chain reaction involving $\mathrm{NO}$ and $\mathrm{CO}$. Provided that the amplification factor, called effective chain length (eCL), is known, the concentration of $\mathrm{NO}_{2}$ can be used as a proxy for the peroxy radical concentration in the sampled air. The eCL depends on radical surface losses and must thus be determined experimentally for each individual setup. $\mathrm{NO}_{2}$ is detected by continuous-wave cavity ring-down spectroscopy (cw-CRDS) using an extended cavity diode laser (ECDL) at $408.9 \mathrm{~nm}$. Optical feedback from a V-shaped resonator maximizes transmission and allows for a simple detector setup. CRDS directly yields absorption coefficients, thus providing $\mathrm{NO}_{2}$ concentrations without additional calibration. The optimum $1 \sigma$ detection limit is $0.3 \mathrm{ppbv}$ at an averaging time of $40 \mathrm{~s}$ and an inlet pressure of $300 \mathrm{hPa}$. Effective chain lengths were determined for $\mathrm{HO}_{2}$ and $\mathrm{CH}_{3} \mathrm{O}_{2}$ at different inlet pressures. The $1 \sigma$ detection limit at an inlet pressure of $300 \mathrm{hPa}$ for $\mathrm{HO}_{2}$ is 3 pptv for an averaging time of $120 \mathrm{~s}$.
\end{abstract}

\section{Introduction}

The hydroperoxy radical $\left(\mathrm{HO}_{2}\right)$ and organic peroxy radicals $\left(\mathrm{RO}_{2}, \mathrm{R}\right.$ being an organic chain), hereafter referred to as peroxy radicals, are known for their importance in photochemical reaction cycles both in the stratosphere (Thrush et al., 1998) and troposphere (Monks, 2005). They are very reactive species, and in combination with the hydroxyl radical $(\mathrm{OH})$ play a crucial role in most atmospheric oxidation mechanisms which lead to the formation of $\mathrm{O}_{3}$, peroxyacetyl nitrate (PAN, see Table A1 - list of acronyms), aldehydes and acids. To fully characterize the photochemical activity of the atmosphere, it is therefore highly desirable to include peroxy radical concentrations. Furthermore, for certain environments modeled and measured concentrations disagree to a significant amount, pointing towards a yet unknown radical recycling process (Lelieveld et al., 2008; Hofzumahaus et al., 2009; Whalley et al., 2011). Although their ambient concentrations are generally low, peak mixing ratios of up to 100 pptv have been observed (Burkert et al., 2001a; Hofzumahaus et al., 2009).

The direct measurement of peroxy radicals remains a challenging task due to their high reactivity and thus short lifetime. The only existing technique for direct and speciated measurements is the matrix isolation electron spin resonance (MIESR) Spectroscopy, which traps them in a $\mathrm{LN}_{2}$-cooled $\mathrm{D}_{2} \mathrm{O}$ matrix. The required long sampling times of $\sim 30 \mathrm{~min}$ and the offline analysis in the laboratory by probing their rotational transitions are important limitations of this technique (Mihelcic et al., 1985; Fuchs et al., 2009). Recent direct $\mathrm{HO}_{2}$ detection setups by Djehiche et al. (2011), and Bell et al. (2012), employing cavity ring-down spectroscopy (CRDS) and noise-immune cavity enhanced optical heterodyne molecular spectroscopy (NICE-OHMS), respectively, still lack the necessary sensitivity for ambient measurements.

Other techniques like laser-induced fluorescence (LIF), chemical ionization mass spectrometry (CIMS), and peroxy radical chemical amplification (PeRCA) are used for the indirect measurement of peroxy radicals. All of them have been deployed for airborne measurements as described in more detail in Heard (2006). 
The PeRCA technique determines the sum of peroxy radicals $\left[\mathrm{RO}_{2}^{*}\right]\left(:=\left[\mathrm{HO}_{2}\right]+\sum\left[\mathrm{RO}_{2}\right]\right)$ by facilitating a chain reaction of peroxy radicals into the less reactive species $\mathrm{NO}_{2}$, whose concentration is then measured (Cantrell and Stedman, 1982; Cantrell et al., 1984; Hastie et al., 1991).

The chemical conversion of peroxy radicals to $\mathrm{NO}_{2}$ is achieved by adding $\mathrm{NO}$ and $\mathrm{CO}$ to the sample air in a reactor, thus enabling the reactions

$\mathrm{HO}_{2}+\mathrm{NO} \rightarrow \mathrm{OH}+\mathrm{NO}_{2}$

and

$\mathrm{OH}+\mathrm{CO}+\mathrm{O}_{2}+\mathrm{M} \rightarrow \mathrm{HO}_{2}+\mathrm{CO}_{2}+\mathrm{M}$.

The $\mathrm{HO}_{2}$ radical is thus recycled, initiating the chain reaction.

Similarly, ambient $\mathrm{RO}_{2}$ radicals are contributing to the $\mathrm{NO}_{2}$ concentration by

$\mathrm{RO}_{2}+\mathrm{NO} \rightarrow \mathrm{RO}+\mathrm{NO}_{2}$,

before also taking part in the chain reaction via $\mathrm{HO}_{2}$

$\mathrm{RO}+\mathrm{O}_{2} \rightarrow \mathrm{HO}_{2}+$ aldehydes/carbonyl compounds.

Thus, both $\mathrm{HO}_{2}$ and $\mathrm{RO}_{2}$ convert $\mathrm{NO}$ to $\mathrm{NO}_{2}$ via the chain reaction involving $\mathrm{HO}_{2}$. The contribution of ambient $\mathrm{OH}$ and $\mathrm{RO}$ radicals to the production of $\mathrm{NO}_{2}$ in the reactor can be neglected due to their comparably low abundance in the atmosphere. Note that the efficiency for $\mathrm{RO}_{2}$ conversion is affected by additional terminating reactions depending on their chemical complexity.

The chain reaction increases the sensitivity to peroxy radicals as the number of molecules to measure is multiplied by the length of the chain reaction, the so-called chain length (CL). This CL depends on a series of terminating reactions and physical losses limiting the amplification in the reactor, which have been described in detail elsewhere (Hastie et al., 1991; Clemitshaw et al., 1997; Cantrell et al., 1993; Reichert et al., 2003). The concentration of the added gases (CO and $\mathrm{NO}$ ) and both the reactor shape and its material are critical for the efficiency of those terminating processes. The total conversion into $\mathrm{NO}_{2}$ is additionally affected by any other radical losses of the sampled air before it reaches the reactor where the amplification takes place. These can specially be enhanced by air-surface contacts in a pressure-regulated inlet. The total amplification factor, being called effective chain length (eCL), must therefore be determined experimentally for each particular setup. The eCL can be determined by sampling known peroxy radical mixtures under controlled conditions. Note that eCL $\leq \mathrm{CL}$ as the measured multiplier eCL incorporates radical losses due to the air-surface contact. Chain length calibrations of $\mathrm{HO}_{2}$ and $\mathrm{CH}_{3} \mathrm{O}_{2}$ are appropriate for airborne measurements where these two peroxy radicals are expected to dominate.
For the determination of the peroxy radical concentrations, the PeRCA technique usually operates alternatingly between a so-called "amplification mode" (CO is added, so the chain reaction takes place) and a "background mode" (where $\mathrm{CO}$ is replaced with $\mathrm{N}_{2}$, suppressing the chain reaction). The background concentration $\left[\mathrm{NO}_{2}\right]_{\text {ambient }}$ is enhanced both by species reacting with NO (e.g., ozone) or by being (thermally) decomposed in the inlet (e.g., PAN). This contribution is denoted by $\left[\mathrm{NO}_{2}\right]_{\text {other }}$. Note that peroxy radicals themselves also contribute to this background through their direct reaction with NO. However, their atmospheric abundance is generally lower than $100 \mathrm{pptv}$, thus their contribution is considered to be negligible as the background is dominated by ambient $\mathrm{O}_{3}$ in the ppbv range.

The resulting $\left[\mathrm{NO}_{2}\right]_{\text {meas }}$ concentration measured is thus composed of

$\left[\mathrm{NO}_{2}\right]_{\text {meas }}=\left[\mathrm{NO}_{2}\right]_{\text {ambient }}+\left[\mathrm{NO}_{2}\right]_{\mathrm{other}}+\mathrm{eCL} \times\left[\mathrm{RO}_{2}^{*}\right]$,

where

$\left[\mathrm{RO}_{2}^{*}\right]:=\left[\mathrm{HO}_{2}\right]+\sum\left[\mathrm{RO}_{2}\right]$,

neglecting both $\mathrm{OH}$ and $\sum \mathrm{RO}$. The background mode thus only measures the first two addends of Eq. (1), and the difference in the $\mathrm{NO}_{2}$ concentration between amplification and background mode constitutes the peroxy radical mediated part. Thus

$\Delta\left[\mathrm{NO}_{2}\right]:=\left[\mathrm{NO}_{2}\right]_{\mathrm{ampl}}-\left[\mathrm{NO}_{2}\right]_{\text {backgr }}=\mathrm{eCL} \times\left[\mathrm{RO}_{2}^{*}\right]$.

The PeRCA technique has been complemented by, for example, Chemiluminescence, LIF (Sadanaga et al., 2004), or cavity ring-down spectroscopy (CRDS) for the detection of $\mathrm{NO}_{2}$ (Heard, 2006). A highly sensitive chemical method using chemiluminescence detection is the reaction of $\mathrm{NO}_{2}$ with a luminol (3-aminophthalhydrazide: $\mathrm{C}_{8} \mathrm{H}_{7} \mathrm{~N}_{3} \mathrm{O}_{2}$ ) solution (Maeda et al., 1980). This yields excellent $(3 \sigma)$ detection limits for the total sum of peroxy radicals of $3 \pm 2$ pptv (eCL $=45 \pm 7$, pressure $200 \mathrm{hPa}$, averaging time $20 \mathrm{~s}$, Kartal et al., 2010) and it has been used in numerous measurement campaigns, both ground-based (Cantrell et al., 1993; Clemitshaw et al., 1997; Burkert et al., 2001b; Andrés Hernández et al., 2001; Fleming et al., 2006; AndrésHernández et al., 2013) and airborne (Green et al., 2002; Andrés Hernández et al., 2010; Kartal et al., 2010). Although well established for airborne measurements, the luminol detector still presents some drawbacks, like its range of linearity and the dependency of the sensitivity to humidity and pressure (Wendisch and Brenguier, 2013). In order to overcome these limitations the PeRCEAS instrument was developed at the Institute of Environmental Physics, which employs a variant of laser absorption spectroscopy called CRDS to measure the $\mathrm{NO}_{2}$ concentration. A V-shaped optical resonator provides optical feedback to the employed extended cavity diode laser (ECDL), stabilizing the laser emission 
wavelength and enhancing resonator transmission. The use of an optical method to detect $\mathrm{NO}_{2}$ presents some clear advantages. Optical detection of $\mathrm{NO}_{2}$ is chemically specific, does not require a constant addition of $\mathrm{NO}_{2}$ to assure detector signal linearity, and is not affected by NO which is added to the sampled air. These benefits provide greater freedom in selecting measurement conditions maximizing conversion and amplification parameters (e.g., increasing NO mixing ratios in the reactor for improving the chemical conversion without deteriorating detection sensitivity). Furthermore, the decrease of the sensitivity of the luminol detection at lower pressures limits its use for measurements in the upper layers of the troposphere.

A similar configuration using the PeRCA technique and a CRDS $\mathrm{NO}_{2}$ detector (albeit without optical feedback) is described in Liu et al. (2009), who reported on an instrument for ground-based measurements at standard pressure. It is a combination of a $\mathrm{NO}_{2}$ CRDS detector (Hargrove et al., 2006) and a $5 \mathrm{~m}$-long (Teflon) tubing system enabling the peroxy radical chemical conversion. Its eCL is calibrated using rather high amounts (compared to typical atmospheric abundances) of $\mathrm{HO}_{2}$ between 0.5 and 3 ppbv generated by thermal decomposition of $\mathrm{H}_{2} \mathrm{O}_{2}$ (see Sect. 3.2 for the PeRCEAS chain length calibration). Investigation of the dependency of the eCL on ambient air humidity is not mentioned. The $\mathrm{NO}_{2}$ detector employs a Nd-YAG pumped dye laser and a resonator incorporating mirrors with a distance of $1 \mathrm{~m}$ (see Sect. 2.2 for the PeRCEAS NO $\mathrm{N}_{2}$ detector description).

CRDS is a technique well known for its sensitivity and robustness. Already employed in 1988 for absorption measurements (O'Keefe and Deacon, 1988), it is nowadays one of the dominant trace gas absorption measurement techniques. Reviews of this spectroscopy method may be found in Busch and Busch (1999), or, more recently, in Berden and Engeln (2010). Briefly, a resonator consisting of highly reflective mirrors is filled with the sample air to be measured. Usually a laser is used for resonator excitation, and if an operatorset resonator transmission intensity is reached, the laser is switched off rapidly. The subsequent decay of this transmission yields the ring-down time $\tau$ after which the intensity has decayed to $e^{-1}$ of its initial value. The losses leading to this decay incorporate absorption and scattering both from the mirrors themselves and from the sample air. The absorption coefficient $\alpha$ of an absorber of interest can be calculated directly from two ring-down time measurements; one with the sample air inside the resonator not containing the absorber (yielding $\tau_{0}$, which also incorporates the mirror reflectivity) and one with the absorber present (yielding $\tau_{\alpha}$ ):

$\alpha=\frac{n}{c_{0}} \times\left(\frac{1}{\tau_{a}}-\frac{1}{\tau_{0}}\right)$,

where $n$ is the index of refraction (here: of the sample air), and $c_{0}$ is the speed of light in vacuum.
The absorber concentration $\frac{N}{V}$ can then be calculated using

$\alpha=\frac{N}{V} \times \sigma_{\text {absorber }}^{\lambda}$,

where $N$ is the number of molecules, $V$ is the volume, and $\sigma_{\text {absorber }}^{\lambda}$ is the absorption cross section at the laser wavelength $\lambda$. Here, the absorber is $\mathrm{NO}_{2}$ and $\sigma_{\mathrm{NO}_{2}}^{408.9 \mathrm{~nm}}=6.5 \times 10^{-19} \mathrm{~cm}^{2}$ molecule ${ }^{-1}$ is the absorption cross section at the laser wavelength of $408.9 \mathrm{~nm}$, a temperature of $296 \mathrm{~K}$ and a pressure of $300 \mathrm{hPa}$ (Vandaele et al., 2002; Nizkorodov et al., 2004). This value was experimentally verified to $\pm 2 \%$ by flowing synthetic air with different $\mathrm{NO}_{2}$ concentrations through the resonator and measuring the corresponding ring-down times (see Sect. 3.1). To determine the peroxy radical concentration, the $\mathrm{NO}_{2}$ concentration difference between background and amplification modes is required. Thus, ring-down measurements taken during the background yield $\tau_{0}$ and those taken during the amplification mode yield $\tau_{\alpha}$ in Eq. (4).

\section{Experimental}

Figure 1 shows the schematic setup of the PeRCEAS instrument developed for operation on the research aircraft HALO (high altitude and long range research aircraft - see http: //www.halo.dlr.de/ for further information). The PeRCEAS instrument can be divided in two main parts; one is the inlet (outer dimension $73 \mathrm{~cm} \times 32 \mathrm{~cm} \times 24 \mathrm{~cm}$; total weight $21 \mathrm{~kg}$ ), which is installed in the aircraft fuselage to sample the outside air, and the other is the $\mathrm{NO}_{2}$ detectors analyzing the sampled (and chemically converted) air. The sampled air proceeds either through a bypass, which is used for the inlet pressure regulation, or to the reactors and $\mathrm{NO}_{2}$ detectors to be measured. The latter air is then scrubbed of $\mathrm{NO}_{\mathrm{x}}$ and $\mathrm{CO}$ before being merged with the bypass flow again. The $\mathrm{NO}_{2}$ detectors are mounted in a customized HALO 19" rack (outer dimension $170 \mathrm{~cm} \times 65 \mathrm{~cm} \times 55 \mathrm{~cm}$; mounted total weight $140 \mathrm{~kg}$ ), which also contains the HALO power supply distribution, a $15^{\prime \prime}$ monitor (VISAM GmbH), a local power distribution unit (Stachl Elektronik $\mathrm{GmbH}$ ), the laser power supply, a DAQ (data acquisition) PXI computer (National Instruments), two Peltier temperature controllers (type MPT 10000, Wavelength Electronics) and one pressure and nine mass flow controllers (Bronkhorst Mättig $\mathrm{GmbH}$ ). The rack bottom also contains a drawer which houses a 600 ppmv $\mathrm{NO}$ in $\mathrm{N}_{2}$ - and a 10 ppmv $\mathrm{NO}_{2}$ in synthetic air gas cylinder and the corresponding pressure reducers. The $\mathrm{NO}_{2}$ is to be used to seed outside air for a reference measurement if the measurement data indicates unusual instrument operation, for example, strongly degraded background ring-down times. Figure 2 shows the assembled PeRCEAS rack.

Additionally required components are a pure $\mathrm{CO}$ and a $\mathrm{N}_{2}$ gas cylinder, a $\mathrm{NO}_{\mathrm{x}}$ and a $\mathrm{CO}$ scrubber, and a vacuum 


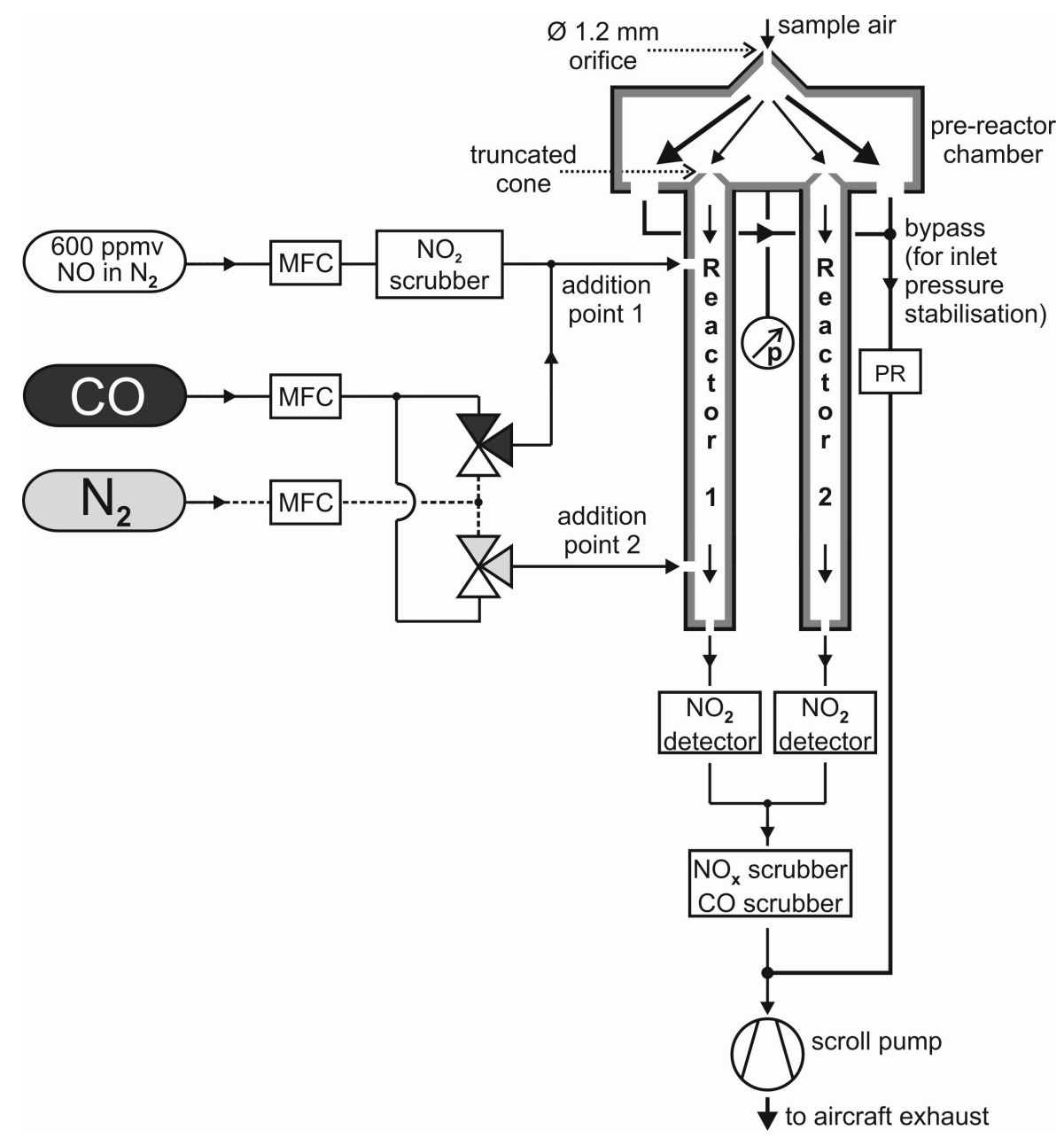

Fig. 1. Pressure and gas flow of the PeRCEAS instrument. Reactor 1 is shown in amplification mode. MFC - mass flow controller, PR pressure regulator. The sensor between both reactors measures the inlet pressure. The ovals on the left side represent gas cylinders.

pump (Scrollvac SC 30 D, Oerlikon Leybold Vakuum). For safety reasons, the $\mathrm{CO}$ gas cylinder is placed in a specially designed containment. The whole system including the inlet has a weight of $250 \mathrm{~kg}$.

\subsection{Inlet}

To avoid certification costs for a nonstandard gas inlet, the size and shape of the PeRCEAS inlet were designed to fit inside a HALO outer protection pylon for standard trace gas inlets. Figure 3 shows a photograph of the PeRCEAS inlet. It was developed based on previous experience with a DUALER (dual channel chemical amplifier - Kartal et al., 2010; Chrobry, 2013). The inlet is made of Teflon-coated stainless steel and consists of a pressure-controlled prereactor chamber (volume $\sim 100 \mathrm{~cm}^{3}$ ), into which the sample air is sucked through a cone with a $1.2 \mathrm{~mm}$ orifice at its top, and two complete reactor-detector sampling lines running in parallel. Inside the reactors (inner diameter $17 \mathrm{~mm}$, length $500 \mathrm{~mm}$, volume $\sim 110 \mathrm{~cm}^{3}$ ) the amplified conversion of peroxy radicals to $\mathrm{NO}_{2}$ takes place. They are directly connected to the two CRDS $\mathrm{NO}_{2}$ detectors via $1 / 4^{\prime \prime}$ outer diameter black PFA tubing. The availability of two parallel sampling lines increase the instrument's reliability and allows continuous monitoring of the $\mathrm{NO}_{2}$ background and its shortterm variations.

The PeRCEAS pre-reactor chamber pressure is stabilized using a pressure sensor (type DMP 331, BD Sensors $\mathrm{GmbH}$ )/pressure regulator (Bronkhorst Mättig $\mathrm{GmbH}$ ) combo. Two transparent $1 / 2^{\prime \prime}$ outer diameter PFA connections on both sides of the pre-reactor chamber allow for the removal of the surplus air by the pressure regulator. Inlet pressure stabilization maintains a constant peroxy radical conversion time and thus eliminates the eCL dependence on the ambient pressure. In the lower troposphere it also significantly reduces the relative humidity and thus the humiditydependent eCL variation (Kartal et al., 2010).

The optimum inlet pressure seeks to enable the measurement at high altitudes with suitable stability and sensitivity. 


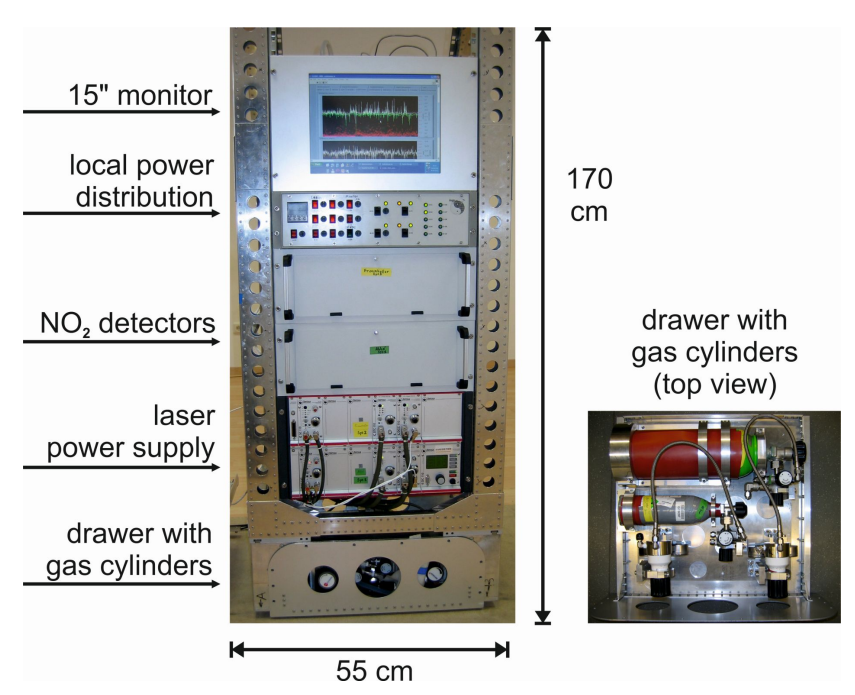

Fig. 2. PeRCEAS rack front side. Rack components which are not visible: PXI computer, temperature-, pressure- and flow controllers, and HALO power supply unit.

Very low pressures at the inlet imply however a deterioration in the eCL and the overall measurement stability. Therefore, an approach as shown in Fig. 4 is proposed. For altitudes below $8 \mathrm{~km}$, the gas flow and pressure controlling is robust at a set inlet pressure of $300 \mathrm{hPa}$, leading to eCL values of around 100 (see Sect. 3.2 for a complete discussion) with a moderate time response of $15 \mathrm{~s}$. For altitudes between 8 and $10 \mathrm{~km}$ an inlet pressure of $200 \mathrm{hPa}$ yields a lower eCL of around 55 with a faster time response of $10 \mathrm{~s}$, whereas at higher altitudes the set inlet pressure of $100 \mathrm{hPa}$ retains these $10 \mathrm{~s}$, as only half of the sample flow can be achieved by the actual setup under these conditions.

During the amplification mode a mixture of $0.09 \mathrm{sLpm}$ pure $\mathrm{CO}$ and $0.01 \mathrm{sLpm} 600 \mathrm{ppmv} \mathrm{NO}$ in $\mathrm{N}_{2}$ is added to the sampled air at the reactor top (addition point 1, Fig. 3), whereas $0.09 \mathrm{sLpm} \mathrm{N}_{2}$ is added at the reactor bottom (addition point 2). In the background mode, the $\mathrm{CO}$ and $\mathrm{N}_{2}$ addition is exchanged $\left(\mathrm{N}_{2}\right.$ and $\mathrm{NO}$ addition at the reactor top, $\mathrm{CO}$ at the reactor bottom). The total reactor flow of $1 \mathrm{sLpm}$ and the mixing ratios of the added gases remain constant during the measurement ( $81 \%$ vol sample air, $9 \%$ vol CO, $\sim 10 \%$ vol $\mathrm{N}_{2}$, and 6 ppmv $\mathrm{NO}$ ). The $\mathrm{CO}$ mixing ratio of $9 \%$ vol ensures a high chain length but is still well below the $12 \%$ vol mixing ratio that poses the danger of creating explosive mixtures. The rerouting of the added gases between the addition points is facilitated by Teflon three-way solenoid valves (type QE 622, Staiger $\mathrm{GmbH}$ ). The NO gas is scrubbed by $\mathrm{FeSO}_{4}$, removing non-negligible traces of $\mathrm{NO}_{2}$, before being added to the gas stream of the reactor top.

To ensure a thorough mixing of the sample air with the added gases, the latter are distributed by eight circularly arranged $\varnothing 1.5 \mathrm{~mm}$ orifices into the reactor. The cylindrical reactors end at the top in a truncated cone ( $4 \mathrm{~mm}$ top diameter,

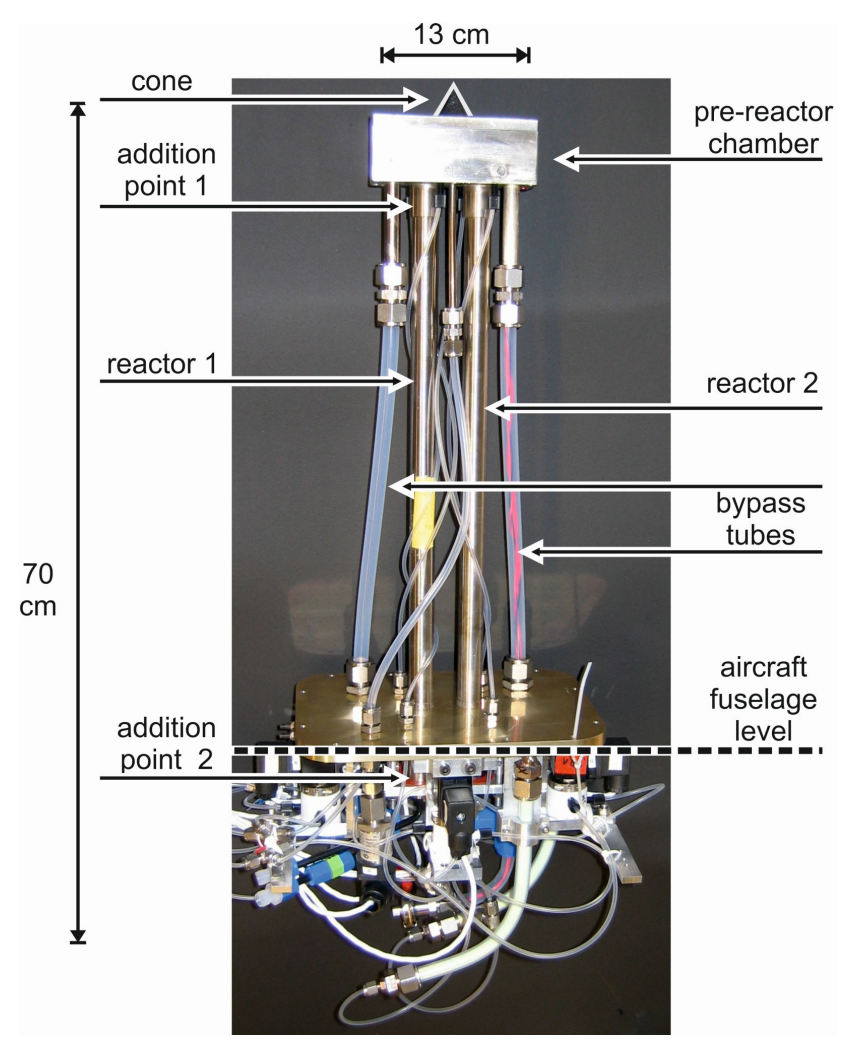

Fig. 3. Side view of the PeRCEAS inlet. Not shown: outer aircraft protection pylon and inner aircraft protection casing.

$14.2 \mathrm{~mm}$ height) protruding into the pre-reactor chamber. The shape and dimensions of these reactor inlets have been selected to prevent diffusion of the added gases into the prereactor chamber while minimizing the radical wall losses.

The PeRCEAS inlet was characterized regarding its operating conditions at an inlet pressure of $300 \mathrm{hPa}$ utilizing a luminol chemiluminescence $\mathrm{NO}_{2}$ detector (Chrobry, 2013). It was found that a Teflon-coated interior of both the prereactor chamber and the reactor doubles the eCL, emphasizing the importance of the choice of material to avoid radical wall losses.

\section{$2.2 \mathrm{NO}_{2}$ detector}

The $\mathrm{NO}_{2}$ detectors in their current stage stem from research on optical feedback cavity-enhanced absorption spectroscopy (OF-CEAS), as reported in Morville et al. (2005), and Courtillot et al. (2006). Briefly, a V-shaped resonator consisting of three highly reflective mirrors is excited via a wavelength-scanning continuous-wave laser. Optical feedback from the resonator forces the laser to stabilize itself onto a resonance frequency, yielding broad transmission lines. Resonator optical losses can be calculated from these transmissions if their maxima are calibrated with a ring-down time measurement. OF-CEAS thus outputs absorption spectra with a wavelength resolution governed by the resonator's 


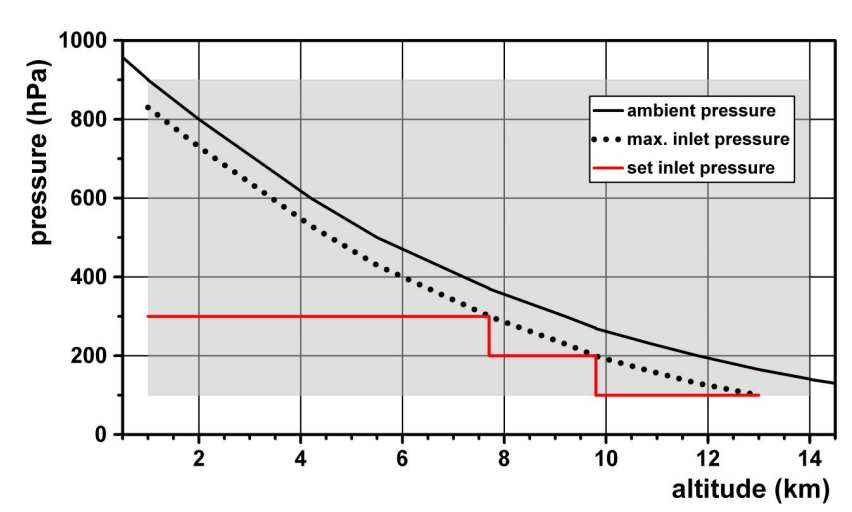

Fig. 4. Operating range of HALO aircraft measurements (shaded area). Maximum inlet pressure is assumed to be always $70 \mathrm{hPa}$ lower than ambient pressure. The proposed set inlet pressure is shown in red. For an inlet pressure of $100 \mathrm{hPa}$ the reactor flow must be reduced from 1 to $0.5 \mathrm{sLpm}$.

free spectral range. For an optimum configuration the distance between laser and resonator must be stabilized (usually by a mirror mounted on a piezo stack) using the symmetry of the transmission lines as an error signal.

The effect of optical feedback was characterized (Horstjann et al., 2012), and resonator transmissions with and without it during a laser scan can be seen in Fig. 5. The laser linewidth decreases about three orders of magnitude, and is temporarily locked to the resonator, yielding high resonator transmission (up to $1 \%$ of the input power) which can be captured by a common Si photodiode detector.

The $\mathrm{NO}_{2}$ detection limit for the detector using the OFCEAS technique was determined to be $\sim 4 \mathrm{ppbv}$ for $1 \mathrm{~s}$ averages and a resonator pressure of $290 \mathrm{hPa}$. For the detection of $\mathrm{NO}_{2}$ in an aircraft environment, the OF-CEAS detection scheme proved to be too susceptible to both temperature variation and vibration, therefore the more robust technique of cavity ring-down spectroscopy (CRDS) was implemented. The continued use of the V-resonator allows the optical feedback to still provide high resonator transmission and bypasses the need for an optical isolator between laser and resonator.

The setup of the detector is shown schematically in Fig. 6 while Fig. 7 shows a photo of the $19^{\prime \prime}$ case containing the ECD Laser (type DL-100L, wavelength $408.9 \mathrm{~nm}$, max. $13 \mathrm{~mW}$ output power, $20 \mathrm{GHz}$ modehop free tuning range, Toptica Photonics AG), the Si photodiode detector (type HCA-S, bandwidth $2 \mathrm{MHz}$, gain $5 \times 10^{5} \mathrm{VA}^{-1}$, Femto Messtechnik $\mathrm{GmbH}$ ), a DAQ connection board, a power supply distribution board, a piezo stabilizing circuit (Floralis, France) and a fast TTL switch-off signal generator (Stachl Elektronik $\mathrm{GmbH}$ ), cables, and gas flow components. The optical detector consists of an aluminium cuboid with a recess, forming a cavity. All optical components are fixed onto this cuboid; in other words, a $\lambda / 2$ plate/polarization beam splitter combo (to adjust the optical feedback level), a prism

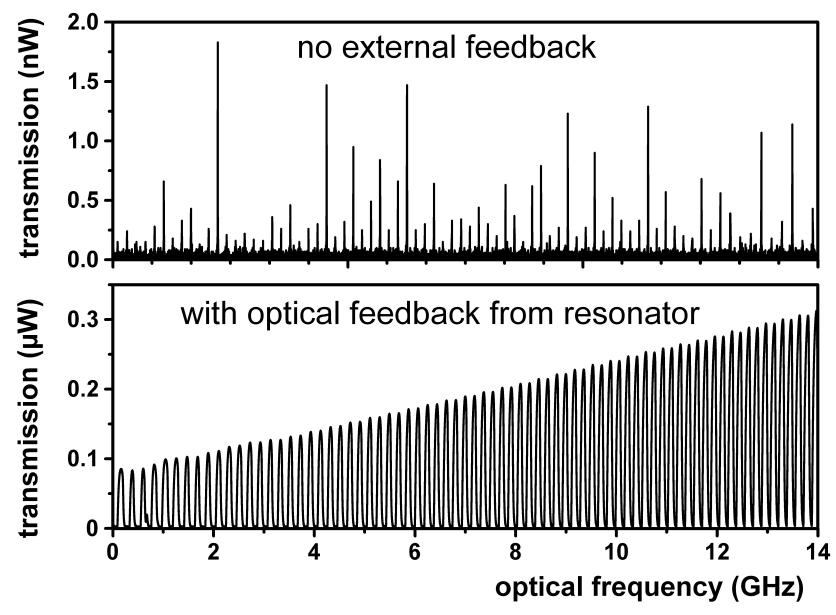

Fig. 5. Resonator transmission vs. relative laser frequency (at a wavelength of $408.9 \mathrm{~nm})$ during a piezo scan $(14 \mathrm{GHz}=7.8 \mathrm{pm}$ at $408.9 \mathrm{~nm}$ ) of the laser grating (Horstjann et al., 2012). Freely running ECDL (top panel); with the optical feedback from the highfinesse V-resonator (bottom panel). The signal slope is due to higher laser power at the end of the wavelength scan.

on a manual linear stage (coarse adjustment of the laserresonator distance), a mirror mounted onto a piezo stack (type P885.10, PI Ceramic GmbH) for fine adjustment of the laser-resonator distance, and the photodiode detector. The cuboid is mechanically isolated from the $19^{\prime \prime}$ chassis by steel springs, and temperature isolated through $2 \mathrm{~mm}$-thick aluminium sheets covered with Armaflex AF isolation material (Armacell Enterprise $\mathrm{GmbH}$ ). Its temperature is also actively stabilized by a Peltier element (type CP-031, Te Technology Inc.). The sample air flow enters in the cuboid center and exits on both ends through NPT-threaded connections, and its temperature, pressure and relative humidity are measured. No aerosol or other gas filtering is used, and no adverse effects from mirror exposure to ambient air was experienced. At an inlet pressure of $300 \mathrm{hPa}$, the retention time of the sample air inside the resonator is $\sim 5 \mathrm{~s}$.

The V-resonator is formed by a recess in the cuboid (volume $\sim 300 \mathrm{~cm}^{3}$ ), sealed on top by a glued-in lid and on its sides by the glued-in highly reflective mirrors (diameter $1 / 2^{\prime \prime}$, roc $100 \mathrm{~cm}$, AT Films, USA). The lid itself contains small plates sealed with o-rings, which can be opened to clean the mirrors. The mirror-to-mirror distance is $40 \mathrm{~cm}$, and the measured vacuum peak ring-down times of $\sim 26 \mu \mathrm{s}$ yield an average mirror reflectivity of $99.995 \%$ and a maximum light path of $\sim 8 \mathrm{~km}$. For a resonator pressure of $285 \mathrm{hPa}$, the ring-down time is $\sim 20 \mu \mathrm{s}$ and the light path thus $\sim 6 \mathrm{~km}$. The laser is wavelength-scanned over $\sim 5 \mathrm{pm}$ (about $10 \mathrm{GHz}$ ), generating $\sim 50$ ring-down times per second. Each ring-down event is sampled for $300 \mu \mathrm{s}$. The ring-down times garnered in the amplification and background modes directly yield the absorption coefficient of the $\mathrm{NO}_{2}$ that was formed by the peroxy radical chemical conversion. Changing 


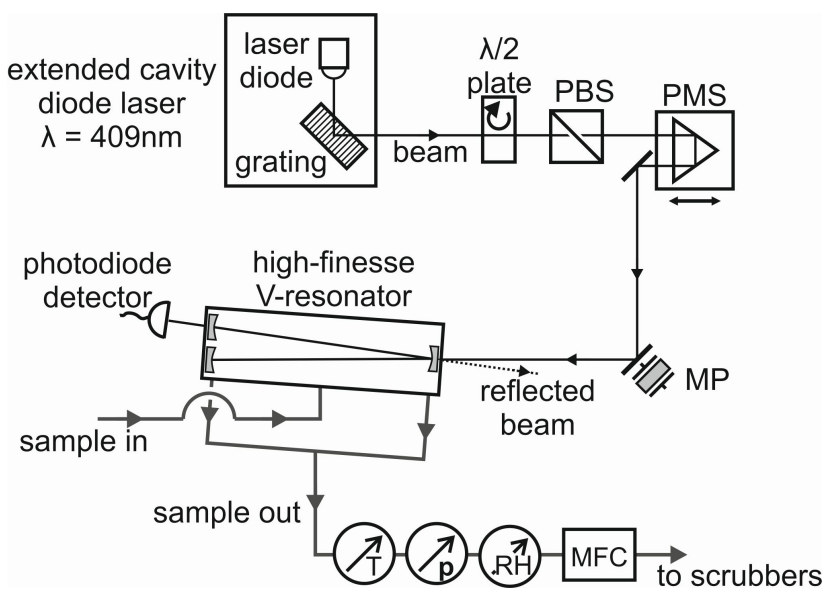

Fig. 6. Schematic diagram of a PeRCEAS $\mathrm{NO}_{2}$ detector. PBS - polarizing beamsplitter, PMS - prism with micrometer screw, MP mirror with piezo, MFC - mass flow controller. The sensors shown measure the temperature $(T)$, pressure $(p)$ and relative humidity $(\mathrm{RH})$ of the sample gas. The use of the V-resonator allows for optical feedback, providing high transmission and obviating the need of an optical isolator between laser and resonator.

background concentrations of substances contributing to the $\mathrm{NO}_{2}$ background are thus automatically accounted for if the change is slow compared to the duration of one background/amplification mode measurement $(60 \mathrm{~s}$ in the present work).

The detector exhaust flows are purified by an activated charcoal scrubber removing the $\mathrm{NO}_{\mathrm{x}}$ traces and a $\mathrm{Pt} / \mathrm{Al}$ pellets scrubber converting $\mathrm{CO}$ to $\mathrm{CO}_{2}$ at temperatures $T>195^{\circ} \mathrm{C}$ before being merged with the inlet bypass flow (Fig. 1). The laser is scanned over $10 \mathrm{GHz}$ at a wavelength of $408.9 \mathrm{~nm}$, and if an operator-set resonator transmission intensity is reached, a fast $(<1 \mu \mathrm{s})$ TTL signal is generated and fed to a FET circuit in parallel to the laser diode which then bypasses the laser diode, effectively switching off the laser. The ring-down signal is then sampled with (1 MSample) $\mathrm{s}^{-1}$ by a PXI-DAQ card (type PXI-6132, National Instruments), saved and analyzed with a PXI-computer (PXI-8105) by a custom LabVIEW program performing non-linear least-squares fits (Levenberg-Marquardt algorithm). The software provides $1 \mathrm{~s}$-averaged ring-down values for online monitoring. Pressure-, flow-, temperature- and humidity sensor data are sampled at (1 Sample) $\mathrm{s}^{-1}$ (PXI-6129) and shown also by the LabVIEW program.

\section{Results and discussion}

Accurate calculation of peroxy radical mixing ratios demands the knowledge of both the eCL and the $\mathrm{NO}_{2}$ mixing ratio difference $\Delta x_{\mathrm{NO}_{2}}$ introduced by the peroxy radical conversion. The latter is straightforward as the CRDS technique yields absorption coefficients that translate into

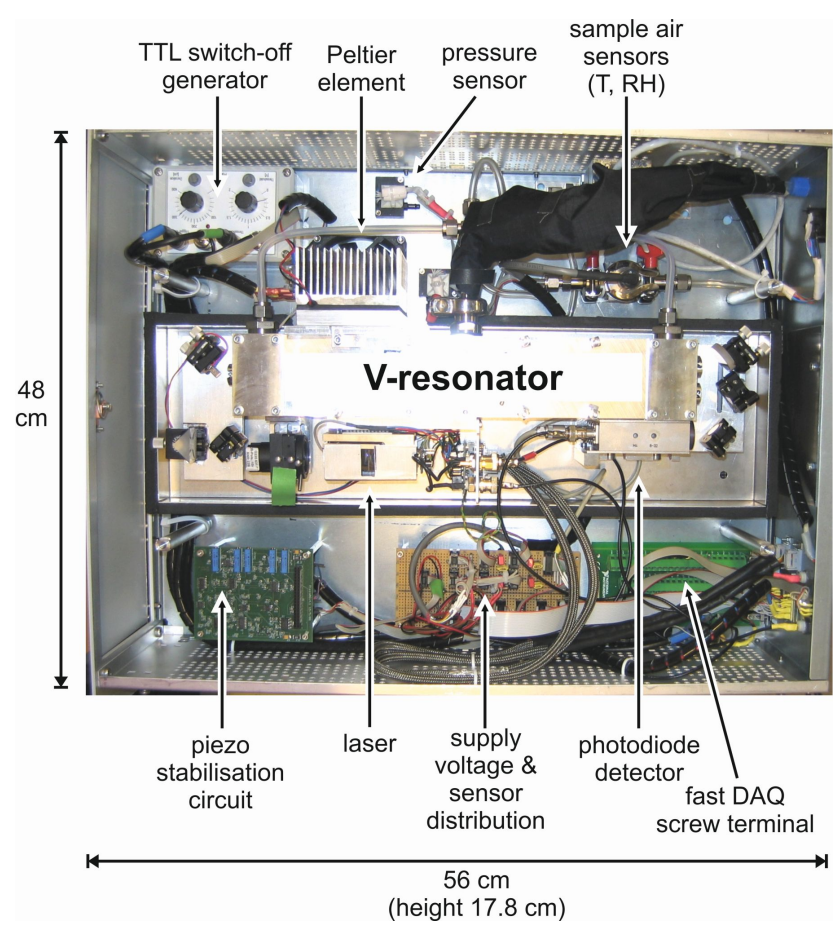

Fig. 7. Top view of the PeRCEAS $\mathrm{NO}_{2}$ detector. The detector fits inside a $18 \mathrm{~cm}$-high $19^{\prime \prime}$ case whose front (here: left-hand side) can be opened. All electrical and gas connections are on its rear panel (here: right-hand side).

concentrations if the absorption cross section $\sigma_{\mathrm{NO}_{2}}$ is known. Volume mixing ratios can then be calculated with the temperature and pressure of the sample air. The detector sensitivity was firstly determined by analyzing the ring-down time variations of a gas mixture of 53 and $107 \mathrm{ppbv} \mathrm{NO}_{2}$ in synthetic air, as this reflects the expected background conditions of in situ measurements. Secondly, the eCL of $\mathrm{HO}_{2}$ and $\mathrm{CH}_{3} \mathrm{O}_{2}$ of the PeRCEAS instrument were experimentally determined for an inlet pressure of $300 \mathrm{hPa}$ by generating a set of known $\mathrm{HO}_{2}$ and $50 \% \mathrm{HO}_{2} / 50 \% \mathrm{CH}_{3} \mathrm{O}_{2}$ volume mixing ratios. The $\mathrm{HO}_{2}$ effective chain length is then determined by $\mathrm{eCL}=\Delta x_{\mathrm{NO}_{2}} / x_{\mathrm{HO}_{2}}$, and the $\mathrm{CH}_{3} \mathrm{O}_{2}$ chain length is deduced from the chain length calibration of the $50 \% / 50 \%$ radical mixture. The peroxy radical detection limit can then be calculated by dividing the $\mathrm{NO}_{2}$ detection limit by the eCL.

\section{1 $\quad \mathrm{NO}_{2}$ detection limit}

To assess the detection limit of the $\mathrm{NO}_{2}$ optical detector, a reference measurement of two different $\mathrm{NO}_{2}$ volume mixing ratios in synthetic air over the expected range of ambient ozone concentrations was analyzed. The $\mathrm{NO}_{2}$ /synthetic air mixture was provided to the inlet cone, and a flow of $1 \mathrm{sLpm}$ was drawn by the detectors. The inlet chamber pressure was kept constant at $300 \mathrm{hPa}$. Figure 8 shows exemplary $1 \mathrm{~s}$ averages of the ring-down times recorded from one detector. 


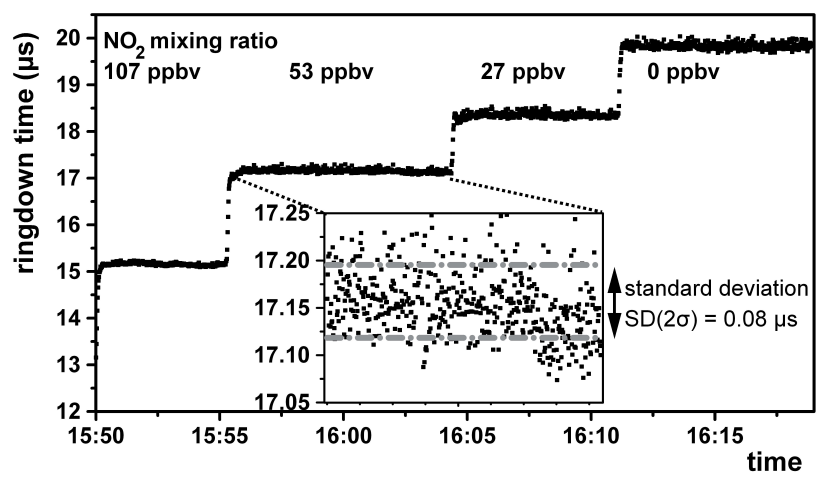

Fig. 8. Ring-down measurement of different $\mathrm{NO}_{2}$ volume mixing ratios in synthetic air.

The measurement yields a value of the absorption cross section of $\sigma_{\mathrm{NO}_{2}}^{4089 \mathrm{~nm}}=6.5 \times 10^{-19} \mathrm{~cm}^{2}$ molecule ${ }^{-1}$ with a relative error of $\pm 2 \%$ at the laser wavelength of $408.9 \mathrm{~nm}$, a temperature of $296 \mathrm{~K}$ and a pressure of $300 \mathrm{hPa}$, in very good agreement with measurements of Vandaele et al. (2002) and Nizkorodov et al. (2004). The cited profiles may be used without requiring a convolution with the laser linewidth of $1 \mathrm{MHz} \sim 6 \times 10^{-4} \mathrm{pm}$ or the laser wavelength scanning range of $10 \mathrm{GHz} \sim 5 \mathrm{pm}$ as both values are small compared to the cross-section profile structures.

The $1 \sigma$ standard deviation for the ring-down time of both the $53 \mathrm{ppbv}$ and $107 \mathrm{ppbv} \mathrm{NO}_{2}$ measurement is below $0.04 \mu \mathrm{s}$, corresponding to a minimum detection limit of the absorption coefficient of $4.6 \times 10^{-9} \mathrm{~cm}^{-1}(\sqrt{\mathrm{Hz}})^{-1}$ or a volume mixing ratio of $1 \mathrm{ppbv}(\sqrt{\mathrm{Hz}})^{-1}$ at an inlet pressure of $p=300 \mathrm{hPa}$ and a temperature of $T=296 \mathrm{~K}$.

Figure 9 shows the corresponding Allan variances (Allan, 1966), indicating an optimum averaging time of $\sim 40 \mathrm{~s}$ for the $53 \mathrm{ppbv}$ mixture with a minimum $(1 \sigma)$ detectable mixing ratio of $0.3 \mathrm{ppbv}$ (or a concentration of $2 \times 10^{9}$ molecules $\mathrm{cm}^{-3}$ ). Longer averaging times are influenced by slow temperature drifts affecting both the laser and the resonator characteristics. For peroxy radical measurements the duration of a background and amplification mode is set to $60 \mathrm{~s}$ to additionally allow the gas flow to settle about $15 \mathrm{~s}$. The $\mathrm{NO}_{2}$ detector sensitivity was tested for different concentrations of $\mathrm{H}_{2} \mathrm{O}, \mathrm{CO}$ and $\mathrm{NO}$, and no significant variation was observed. The present $\mathrm{NO}_{2}$ detection limit is adequate for the peroxy radical measurement task, but is limited by the characteristics of the laser source used. Different types of broadband diode lasers without extended cavities are at the moment investigated as possible improvements. Initial laboratory characterizations using a similar V-resonator show promising results in the form of decreased ring-down time noise.

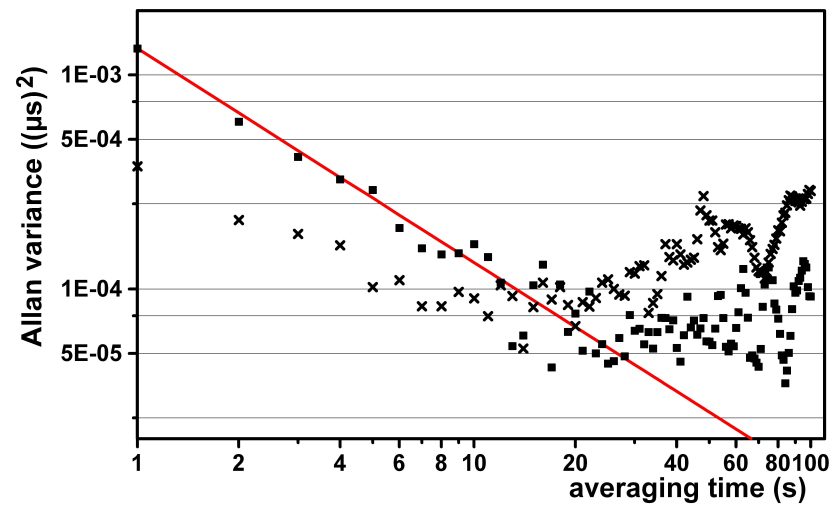

Fig. 9. Allan variance of the $53 \mathrm{ppbv} \mathrm{NO}_{2}$ (black dots) and the 107 ppbv $\mathrm{NO}_{2}$ (black crosses) in synthetic air measurement as depicted in Fig. 8. The red line corresponds to the black dots and indicates a slope of -1.0 , which is expected for white noise only.

\subsection{Effective chain length calibration}

The effective chain lengths of the PeRCEAS instrument were calibrated using a peroxy radical source introduced by Schultz et al. (1995); the employed model resembling the one characterized by Stöbener (1999), and described in detail by Reichert et al. (2003). Briefly, synthetic air is enriched with a known amount of water, flown through a quartz glass tube and provided to the PeRCEAS inlet. Shortly before being sucked in, the air is illuminated by a $\mathrm{Hg} / \mathrm{Ne}$ gas UV lamp (type Pen-Ray, LOT-QuantumDesign $\mathrm{GmbH}$ ), thus water is photolysed and $\mathrm{HO}_{2}$ is produced by the reaction of hydrogen with oxygen. A photomultiplier tube (PMT, type 1259 with a $\mathrm{MgF}_{2}$ window; Hamamatsu Photonics) measures a portion of the transmitted intensity afterwards. Addition of $0.1 \%$ vol $\mathrm{CO}$ assures the complete conversion to $\mathrm{HO}_{2}$ by reacting with both the hydroxyl radical and oxygen. Addition of $1.6 \%$ vol $\mathrm{CH}_{4}$ instead produces a $50 \% / 50 \%$ mixture of $\mathrm{HO}_{2}$ and $\mathrm{CH}_{3} \mathrm{O}_{2}$.

For the pure $\mathrm{HO}_{2}$ configuration, its concentration can be calculated using

$\left[\mathrm{HO}_{2}\right]=\frac{\sigma_{\mathrm{H}_{2} \mathrm{O}}^{184.9 \mathrm{~nm}}}{\sigma_{\mathrm{O}_{2}}^{184.9 \mathrm{~nm}}} \times \frac{\left[\mathrm{H}_{2} \mathrm{O}\right]}{\left[\mathrm{O}_{2}\right]} \times\left[\mathrm{O}_{3}\right]$,

where $\quad \sigma_{\mathrm{H}_{2} \mathrm{O}}^{184.9 \mathrm{~nm}}=(7.14 \pm 0.10) \times 10^{-20} \mathrm{~cm}^{2}$ molecule ${ }^{-1}$ is the absorption cross section of $\mathrm{H}_{2} \mathrm{O}$ at $184.9 \mathrm{~nm}$ (Cantrell et al., 1997; the denoted error represents the $\pm 1 \sigma$ standard deviation), and $\sigma_{\mathrm{O}_{2}}^{184.9 \mathrm{~nm}}=(1.60 \pm 0.08) \times 10^{-20} \mathrm{~cm}^{2}$ molecule ${ }^{-1}$ is the effective absorption cross section of $\mathrm{O}_{2}$, which has been determined specifically for the radical source employed here according to Hofzumahaus et al. (1997); the denoted error represents the $\pm 1 \sigma$ standard deviation (Kartal, 2009). $\left[\mathrm{H}_{2} \mathrm{O}\right]$ is calculated from measurements of a dew point sensor (type DMP 248, Vaisala $\mathrm{GmbH}$ ). $\left[\mathrm{O}_{2}\right]$ is given by 


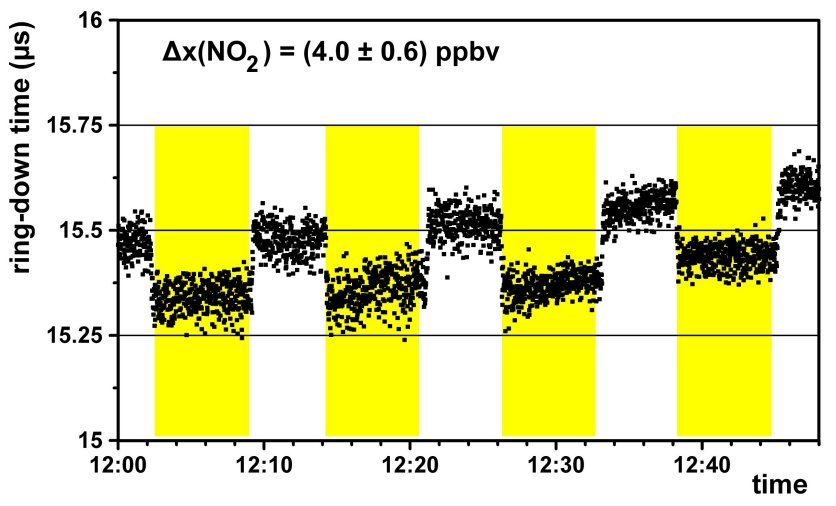

Fig. 10. Measurement of the maximum ozone concentration generated by the radical source. Periods with UV light entering the source are marked in yellow.

the specifications of the used synthetic air gas cylinder (type Alphagaz, Air Liquide Deutschland $\mathrm{GmbH}$ ).

To generate a range of different $\mathrm{HO}_{2}$ or $\mathrm{CH}_{3} \mathrm{O}_{2}$ concentrations, pure $\mathrm{N}_{2} \mathrm{O}$ gas is used as an optical filter (Cantrell et al., 1997) and absorbs part of the UV light reaching the photolysis zone. The measured PMT signal $I$ is used as an $\left[\mathrm{O}_{3}\right]$ proxy (Reichert et al., 2003):

$\frac{\left[\mathrm{O}_{3}\right]}{\left[\mathrm{O}_{3}^{\max }\right]}=\frac{I}{I_{\max }}$.

The maximum ozone concentration $\left(\left[\mathrm{O}_{3}^{\max }\right]\right)$ generated by the radical source was measured in the PeRCEAS $\mathrm{NO}_{2}$ detector while adding $0.01 \mathrm{sLpm}$ of $600 \mathrm{ppmv} \mathrm{NO}$ in $\mathrm{N}_{2}$ to the reactor to convert the ozone to $\mathrm{NO}_{2}$. The UV light was modulated by means of a mechanical shutter every 7 minutes for a 5-minute background measurement. Figure 10 shows a measurement at an inlet pressure of $300 \mathrm{hPa}$ which lasted $45 \mathrm{~min}$. The ring-down time differences yield $x\left(\mathrm{O}_{3}^{\max }\right)=(4.0 \pm 0.6) \mathrm{ppbv}$, which together with the PMT measurement $I_{\max }=3.54 \mathrm{~V}$ results in $x\left(\mathrm{O}_{3}^{\max }\right) / I_{\max } \sim(1.13 \pm 0.17) \mathrm{ppbv}^{-1}$. This ratio is in reasonable agreement with a value of $(1.06 \pm 0.03) \mathrm{ppbv} \mathrm{V}^{-1}$ determined with a luminol chemiluminescence detector.

For the radical source used in this experiment, the mixing ratios are $x\left(\mathrm{O}_{3}^{\max }\right) \sim 4 \mathrm{ppbv}, x\left(\mathrm{H}_{2} \mathrm{O}\right) \sim 2000 \mathrm{ppmv}$, and $x\left(\mathrm{O}_{2}\right) \sim 20 \%$ vol, thus $x\left(\mathrm{HO}_{2}^{\max }\right) \sim 200$ pptv.

The $1 \sigma$ relative uncertainty of the $\mathrm{HO}_{2}$ concentration amounts to $\pm 17 \%$, and consists of the uncertainties for the absorption cross sections of $\mathrm{H}_{2} \mathrm{O}(1.5 \%)$ and $\mathrm{O}_{2}(5 \%)$, for the $\mathrm{H}_{2} \mathrm{O}$ concentration (5\%, from the dew point temperature accuracy of $\pm 2 \mathrm{~K}$ ), and for the $\mathrm{O}_{3}$ concentration $(15 \%)$. The $\mathrm{O}_{2}$ concentration uncertainty is negligible. As was already briefly mentioned in the introduction, the relative uncertainty of the $\mathrm{NO}_{2}$ volume mixing ratio is $\pm 2 \%$. Thus, the $1 \sigma$ relative uncertainty of the eCL calculation is $\pm 19 \%$.

Multiple eCL calibrations for both $\mathrm{HO}_{2}$ and a $50 \% / 50 \%$ mixture of $\mathrm{HO}_{2}$ and $\mathrm{CH}_{3} \mathrm{O}_{2}$ have been carried out for both

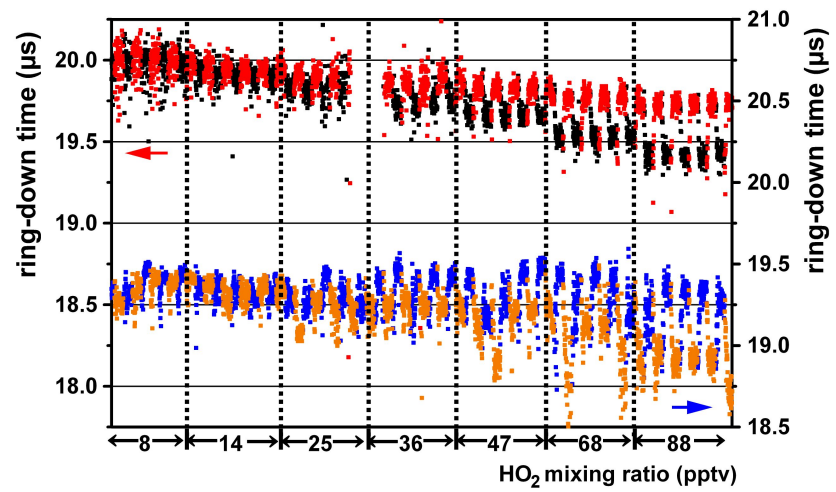

Fig. 11. eCL $\mathrm{HO}_{2}$ calibration measurement at an inlet pressure of $300 \mathrm{hPa}$. Left $y$ axis: reactor 1, red - background, black - amplification mode measurement. Right $y$ axis: reactor 2 , blue - background, orange - amplification mode measurement. The duration of each $\mathrm{HO}_{2}$ volume mixing ratio measurement was $10 \mathrm{~min}$.

PeRCEAS reactors at different pressure conditions. For this, the radical source stepwise produced $\mathrm{HO}_{2}$ mixing ratios of (10-120) pptv for 10 minutes each, while the PeRCEAS reactors alternate between background and amplification mode every minute. An example of such a measurement at an inlet pressure of $300 \mathrm{hPa}$ can be seen in Fig. 11, while Fig. 12 shows a transition process in detail. The switching of the solenoid valves induces a pressure pulse, and it takes about $15 \mathrm{~s}$ for the gas flow to stabilize itself afterwards. A part of this settling time is caused by the retention time of the sample air inside the reactor $(2 \mathrm{~s})$, the tube connecting the inlet and $\mathrm{NO}_{2}$ detector $(<1 \mathrm{~s})$ and the detector itself $(5 \mathrm{~s})$.

The resulting eCL determination is shown in Fig. 13. The $\Delta \mathrm{NO}_{2}$ values were calculated from the averages of both the background and the amplification mode ring-down times for a constant $\mathrm{HO}_{2}$ volume mixing ratio. In this measurement the effective chain lengths for the two reactors are $\mathrm{eCL}_{\mathrm{HO}_{2}}=82 \pm 17$ for reactor 1 and $\mathrm{eCL}_{\mathrm{HO}_{2}}=103 \pm 21$ for reactor 2 ( $1 \sigma$ uncertainty of $19 \%$ as calculated above).

A total of 11 such calibrations were carried out over multiple days to test their reproducibility. The average effective chain lengths for the two reactors present in PeRCEAS are $\mathrm{eCL}_{\mathrm{HO}_{2}}=88 \pm 17$ for reactor 1 and $\mathrm{eCL}_{\mathrm{HO}_{2}}=110 \pm 21$ for reactor 2 ( $1 \sigma$ uncertainty of $19 \%$ as calculated above). The (statistical) $1 \sigma$ standard deviations of the effective chain lengths of 10 and 9 are well below this uncertainty.

The dissimilar effective chain lengths of both reactors are most probably caused by small differences in their fabrication. Previous studies using luminol $\mathrm{NO}_{2}$ detectors and adding 3 ppmv of NO to the reactors showed effective chain lengths of $79 \pm 9$ and $100 \pm 13$ (Chrobry, 2013). Lower eCL values are expected for these conditions as a NO mixing ratio of around $5 \mathrm{ppmv}$ is expected to yield a maximum eCL.

The $\mathrm{HO}_{2} / \mathrm{CH}_{3} \mathrm{O}_{2}$ mixture yielded effective chain lengths of $\mathrm{eCL}_{\text {mix }}=76 \pm 14$ for reactor 1 and $\mathrm{eCL}_{\text {mix }}=96 \pm 18$ for 


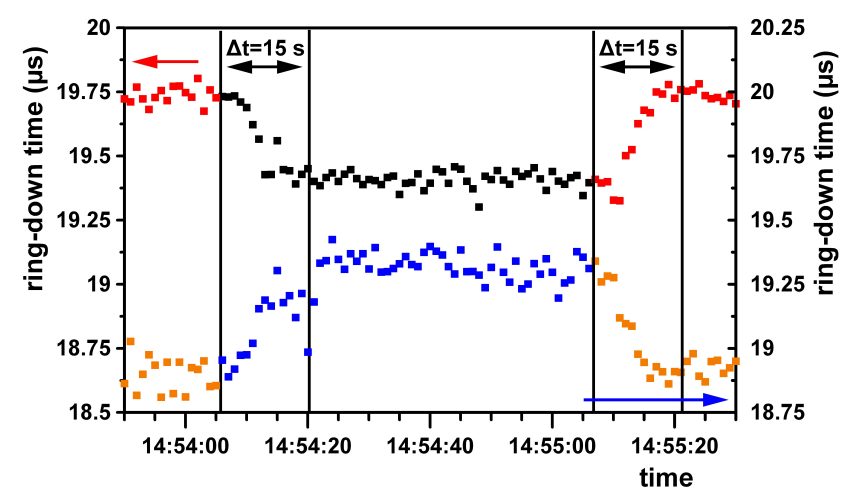

Fig. 12. Switching between background (reactor 1: left $y$ axis, red; reactor 2: right $y$ axis, blue) and amplification mode (reactor 1: left $y$ axis, black; reactor 2: right $y$ axis, orange); the two solid lines indicate a time difference of $15 \mathrm{~s}$ required for the gas flow stabilization.

reactor 2, which leads to effective chain lengths for $\mathrm{CH}_{3} \mathrm{O}_{2}$ of $\mathrm{eCL}_{\mathrm{CH}_{3} \mathrm{O}_{2}}=64 \pm 18$ for reactor 1 and $\mathrm{eCL}_{\mathrm{CH}_{3} \mathrm{O}_{2}}=82 \pm 23$ for reactor 2 . As noted before in the introduction, the smaller effective chain length compared to $\mathrm{eCL}_{\mathrm{HO}_{2}}$ is expected due to additional loss reactions, for example, the direct reaction of $\mathrm{CH}_{3} \mathrm{O}$ with $\mathrm{NO}$. The $1 \sigma$ uncertainty is enhanced by a factor of $\sqrt{2}$ due to the difference being taken of two effective chain length calibrations.

For an inlet pressure of $200 \mathrm{hPa}$ effective chain lengths of $55 \pm 10$ were determined, without significant difference between both reactors. Possible reasons for the effective chain length decrease include higher radical surface losses due to more turbulent flow conditions, a lower radical conversion efficiency due to smaller reactor retention times, and the pressure dependence of contributing reactions (e.g., Reaction R2).

The PeRCEAS instrument reported by Liu et al. (2009) differs both in scope (airborne measurements for PeRCEAS vs. ground-based measurements) and general layout (pressure stabilized inlet of PeRCEAS vs. Teflon tubing inlet, compact 19" $\mathrm{NO}_{2}$ detector with a diode laser for PeRCEAS vs. more voluminous Nd-YAG pumped dye laser setup). Its chain length is reported to be $150 \pm 50$ for standard pressure. Both instruments show peroxy radical $(1 \sigma)$ detection limits of $\sim 3$ pptv, albeit at different averaging times (120 s for PeRCEAS instead of $60 \mathrm{~s}$ ), and at different inlet pressures ( $300 \mathrm{hPa}$ for PeRCEAS instead of $\sim 1000 \mathrm{hPa}$ ).

\section{Summary and conclusion}

The development and characterization of a peroxy radical chemical amplification instrument for airborne measurements with a CRDS $\mathrm{NO}_{2}$ detector using optical feedback are reported. The $\Delta \mathrm{NO}_{2}$ detection by CRDS allows for the direct calculation of the $\mathrm{RO}_{2}^{*}$ volume mixing ratios without

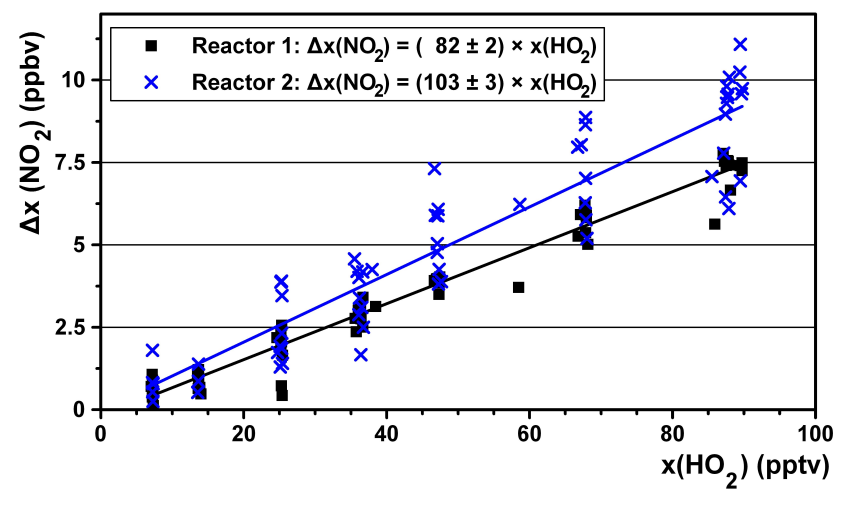

Fig. 13. Effective chain length determination corresponding to the calibration measurement shown in Fig. 11. Shown are the $\Delta \mathrm{NO}_{2}$ vs. $\mathrm{HO}_{2}$ mixing ratios measured for both PeRCEAS reactors. The slopes of the linear fits represent their eCL.

requiring a $\mathrm{NO}_{2}$ calibration, and its sensitivity is free from interference of variations in the humidity and pressure levels. An optimum averaging time of $40 \mathrm{~s}$ yields a $(1 \sigma)$ minimum detectable $\mathrm{NO}_{2}$ mixing ratio of $0.3 \mathrm{ppbv}$ (resonator pressure $285 \mathrm{hPa}$ ).

For an inlet pressure of $300 \mathrm{hPa}$, the effective chain lengths of the reactors are $\mathrm{eCL}_{\mathrm{HO}_{2}}=88 \pm 17$ for reactor 1 and $\mathrm{eCL}_{\mathrm{HO}_{2}}=110 \pm 21$ for reactor 2. For $\mathrm{CH}_{3} \mathrm{O}_{2}$, the values are $\mathrm{eCL}_{\mathrm{CH}_{3} \mathrm{O}_{2}}=64 \pm 18$ for reactor 1 and $\mathrm{eCL}_{\mathrm{CH}_{3} \mathrm{O}_{2}}=82 \pm 23$ for reactor 2 . These values lead to a $(1 \sigma)$ detection limit for the total sum of peroxy radicals $\mathrm{RO}_{2}^{*}$ between 3 and $5 \mathrm{pptv}$ for an averaging time of $120 \mathrm{~s}$ (one background mode and one amplification mode measurement). For an inlet pressure of $200 \mathrm{hPa}$ effective chain lengths for $\mathrm{HO}_{2}$ of $55 \pm 10$ were measured, and thus a $(1 \sigma)$ detection limit for $\mathrm{HO}_{2}$ of $\sim 6 \mathrm{pptv}$ (averaging time of $120 \mathrm{~s}$ ) was determined.

As shown, the PeRCEAS airborne instrument provides a means to accurately measure mixing ratios of peroxy radicals in the pptv range in altitudes of up to $13 \mathrm{~km}$. It is currently certified for aircraft operation, and will take part in the OMO (oxidation mechanisms observations in the extratropical free troposphere) mission onboard the HALO aircraft, whose start is scheduled for end of 2014.

Acknowledgements. We are indebted to the university mechanical workshop, especially for crafting the V-resonators. We acknowledge funding for this study by the University of Bremen, the State of Bremen, and the HALO SPP 1294 (Atmospheric and Earth system research) grant from the DFG Deutsche Forschungsgemeinschaft, including salary funding for the first author.

Edited by: J. Stutz 


\section{References}

Allan, D. W.: Statistics of atomic frequency standards, Proc. IEEE, 54, 221-230, 1966.

Andrés Hernández, M. D., Burkert, J., Reichert, L., Stöbener, D., Meyer-Arnek, J., and Burrows, J. P.: Marine boundary layer peroxy radical chemistry during the AEROSOLS99 campaign: measurements and analysis, J. Geophys. Res., 106, 20833-20846, 2001.

Andrés-Hernández, M. D., Stone, D., Brookes, D. M., Commane, R., Reeves, C. E., Huntrieser, H., Heard, D. E., Monks, P. S., Burrows, J. P., Schlager, H., Kartal, D., Evans, M. J., Floquet, C. F. A., Ingham, T., Methven, J., and Parker, A. E.: Peroxy radical partitioning during the AMMA radical intercomparison exercise, Atmos. Chem. Phys., 10, 10621-10638, doi:10.5194/acp-1010621-2010, 2010.

Andrés-Hernández, M. D., Kartal, D., Crowley, J. N., Sinha, V., Regelin, E., Martínez-Harder, M., Nenakhov, V., Williams, J., Harder, H., Bozem, H., Song, W., Thieser, J., Tang, M. J., Hosaynali Beigi, Z., and Burrows, J. P.: Diel peroxy radicals in a semi-industrial coastal area: nighttime formation of free radicals, Atmos. Chem. Phys., 13, 5731-5749, doi:10.5194/acp-13-57312013, 2013.

Bell, C. L., van Helden, J. P. H., Blaikie, T. P. J., Hancock, G., van Leeuwen, N. J., Peverall, R., and Ritchie, G. A. D.: Noiseimmune cavity-enhanced optical heterodyne detection of $\mathrm{HO}_{2}$ in the near-infrared range, J. Phys. Chem. A, 116, 5090-5099, 2012

Berden, G. and Engeln, R.: Cavity Ring-Down Spectroscopy: Techniques and Applications, John Wiley \& Sons Ltd, The Atrium, Southern Gate, Chichester, West Sussex, UK, doi:10.1002/9781444308259.fmatter, 2010.

Burkert, J., Behmann, T., Andrés Hernández, M. D., Weissenmayer, M., Perner, D., and Burrows, J. P.: Measurements of peroxy radicals in a forested area in Portugal, Chemosphere, 3, 3327-3338, 2001a.

Burkert, J., Andrés Hernández, M. D., Stöbener, D., Burrows, J. P., Weissenmayer, M., and Kraus, A.: Peroxy radical and related trace gas measurement in the marine boundary layer above the Atlantic Ocean, J. Geophys. Res., 106, 5457-5477, 2001b.

Busch, K. W. and Busch, M. A.: Cavity-Ringdown Spectroscopy, American Chemical Society, ACS Copyright Office, Publications Division, Washington, D.C., doi:10.1021/bk-1999-0720, 1999.

Cantrell, C. A. and Stedman, D. H.: A possible technique for the measurement of atmospheric peroxy radicals, Geophys. Res. Lett., 9, 846-849, 1982.

Cantrell, C. A., Stedman, D. H., and Wendel, G. J.: Measurement of atmospheric peroxy radicals by the chemical amplification, Anal. Chem., 56, 1496-1502, 1984.

Cantrell, C. A., Shetter, R. E., Lind, J. A., McDaniel, A. H., and Calvert, J.: An Improved Chemical Amplifier Technique for Peroxy Radical Measurements, J. Geophys. Res., 98, 2897-2909, 1993.

Cantrell, C. A., Zimmer, A., and Tyndall, G. S.: Absorption cross sections for water vapor from 183 to $193 \mathrm{~nm}$, Geophys. Res. Lett., 24, 2195-2198, 1997.

Chrobry, A.: Development and laboratory characterization of a sampling system for airborne measurements of peroxy radicals using chemical amplification, Ph. D. dissertation, University of Bremen, Bremen, 2013.
Clemitshaw, K., Carpenter, L., Penkett, S., and Jenkin, M.: A calibrated peroxy radical chemical amplifier for ground-based tropospheric measurements, J. Geophys. Res., 102, 25405-25416, 1997.

Courtillot, I., Morville, J., Motto-Ros, V., and Romanini, D.: Subppb $\mathrm{NO}_{2}$ detection by optical feedback cavity-enhanced absorption spectroscopy with a blue diode laser, Appl. Phys. B, 85, $407-$ 412, 2006

Djehiche, M., Tomas, A., Fittschen, C., and Coddeville, P.: First cavity ring-down spectroscopy $\mathrm{HO}_{2}$ measurements in a large photoreactor, Z. Phys. Chem., 225, 983-992, doi:10.1524/zpch.2011.0143, 2011.

Fleming, Z. L., Monks, P. S., Rickard, A. R., Heard, D. E., Bloss, W. J., Seakins, P. W., Still, T. J., Sommariva, R., Pilling, M. J., Morgan, R., Green, T. J., Brough, N., Mills, G. P., Penkett, S. A., Lewis, A. C., Lee, J. D., Saiz-Lopez, A., and Plane, J. M. C.: Peroxy radical chemistry and the control of ozone photochemistry at Mace Head, Ireland during the summer of 2002, Atmos. Chem. Phys., 6, 2193-2214, doi:10.5194/acp-6-2193-2006, 2006.

Fuchs, H., Brauers, T., Häseler, R., Holland, F., Mihelcic, D., Müsgen, P., Rohrer, F., Wegener, R., and Hofzumahaus, A.: Intercomparison of peroxy radical measurements obtained at atmospheric conditions by laser-induced fluorescence and electron spin resonance spectroscopy, Atmos. Meas. Tech., 2, 55-64, doi:10.5194/amt-2-55-2009, 2009.

Green, T. J., Reeves, C. E., Brough, N., Edwards, G. D., Monks, P. S., and Penkett, S. A.: Airborne measurements of peroxy radicals using the PERCA technique, J. Environ. Monitor., 5, 75-83, doi:10.1039/B204493E, 2002.

Hargrove, J., Wang, L., Muyskens, K., Muyskens, M., Medina, D., Zaide, S., Zhang, J.: Cavity ring-down spectroscopy of ambient $\mathrm{NO}_{2}$ with quantification and elimination of interferences, Env. Sci. Technol., 40, 7868-7873, 2006.

Hastie, D. R., Weissenmayer, M., Burrows, J. P., and Harris, G. W. Calibrated chemical amplifier for atmospheric $\mathrm{RO}_{\mathrm{x}}$ measurements, Anal. Chem., 63, 2048-2057, 1991.

Heard, D.: Analytical Techniques for Atmospheric Measurement, Blackwell Publishing Ltd, Oxford, UK, $528 \mathrm{pp}$., doi:10.1002/9780470988510, 2006.

Hofzumahaus, A., Brauers, T., Aschmutat, U., Brandenburger, U., Dorn, H. P., Hausmann, M., Heßling, M., Holland, F., PlassDülmer, C., Sedlacek, M., Weber, M., and Ehhalt, D. H.: Reply, Geophys. Res. Lett., 24, 3039-3040, 1997.

Hofzumahaus, A., Rohrer, F., Lu, K., Bohn, B., Brauers, T., Chang, C.-C., Fuchs, H., Holland, F., Kita, K., Kondo, Y., Li, X., Lou, S., Shao, M., Zeng, L., Wahner, A., and Zhang, Y.: Amplified trace gas removal in the troposphere, Science, 324, 17021704, doi:10.1126/science.1164566, 2009.

Horstjann, M., Nenakhov, V., and Burrows, J. P.: Frequency stabilization of blue extended cavity diode lasers by external cavity optical feedback, Appl. Phys. B, 106, 261-266, 2012.

Kartal, D.: Characterization and optimization of a dual channel PERCA for the investigation of the chemistry of peroxy radicals in the upper troposphere, $\mathrm{Ph}$. D. dissertation, University of Bremen, Bremen, 2009. 
Kartal, D., Andrés-Hernández, M. D., Reichert, L., Schlager, H., and Burrows, J. P.: Technical Note: Characterisation of a DUALER instrument for the airborne measurement of peroxy radicals during AMMA 2006, Atmos. Chem. Phys., 10, 30473062, doi:10.5194/acp-10-3047-2010, 2010.

Lelieveld, J., Butler, T. M., Crowley, J. N., Dillon, T. J., Fischer, H., Ganzeveld, L., Harder, H., Lawrence, M. G., Martinez, M., Taraborrelli, D., and Williams, J.: Atmospheric oxidation capacity sustained by a tropical forest, Nature, 452, 737-740, 2008.

Liu, Y., Morales-Cueto, R., Hargrove, J., Medina, D., and Zhang, J.: Measurements of peroxy radicals using chemical amplificationcavity ringdown spectroscopy, Environ. Sci. Technol., 43, 77917796, 2009.

Maeda, Y., Aoki, K., and Munemori, M.: Chemiluminescence Method for the Determination of Nitrogen Dioxide, Anal. Chem., 52, 307-311, doi:10.1021/ac50052a022, 1980.

Mihelcic, D., Müsgen, P., and Ehhalt, D. H.: An improved method of measuring tropospheric $\mathrm{NO}_{2}$ and $\mathrm{RO}_{2}$ by matrix isolation and electron spin resonance, J. Atmos. Chem., 3, 341-361, 1985.

Monks, P.: Gas-phase radical chemistry in the troposphere, Chem. Soc. Rev., 34, 376-395, 2005.

Morville, J., Kassi, S., Chenevier, M., and Romanini, D.: Fast, lownoise, mode-by-mode, cavity-enhanced absorption spectroscopy by diode-laser self-locking, Appl. Phys. B, 80, 1027-1038, 2005.

Nizkorodov, S. A., Sander, S. P., and Brown, L. R.: Temperature dependence of high-resolution air-broadened absorption cross sections of $\mathrm{NO}_{2}$ (415-525 nm), J. Phys. Chem. A, 108, 4864-4872, 2004.

O'Keefe, A. and Deacon, D. A. G.: Cavity ring-down optical spectrometer for absorption measurements using pulsed laser sources, Rev. Sci. Instrum., 59, 2544-2551, 1988.
Reichert, L., Andrés Hernández, M. D., Stöbener, D., Burkert, J., and Burrows, J. P.: Investigation of the effect of water complexes in the determination of peroxy radical ambient concentrations: implications for the atmosphere, J. Geophys. Res., 108, 4017, doi:10.1029/2002JD002152, 2003.

Sadanaga, Y., Matsumoto, J., Sakurai, K., Isozaki, R., Kato, S., Nomaguchi, T., Bandow, H., and Kajii, Y.: Development of a measurement system of peroxy radicals using a chemical amplification/laser-induced fluorescence technique, Rev. Sci. Instrum., 75, 864-872, 2004.

Schultz, M., Heitlinger, M., Mihelcic, D., and Volz-Thomas, A.: Calibration source for peroxy radicals with built-in actinometry using $\mathrm{H}_{2} \mathrm{O}$ and $\mathrm{O}_{2}$ photolysis at $185 \mathrm{~nm}$, J. Geophys. Res. 100, 18811-18816, 1995.

Stöbener, D.: Weiterentwicklung einer Peroxyradikalquelle für die Kalibration von $\mathrm{RO}_{2}$ - Messungen in Außenluft, Diploma thesis, University of Bremen, Bremen, 1999.

Thrush, B. A.: The chemistry of the stratosphere, Rep. Prog. Phys., 51, 1341-1371, 1988.

Vandaele, A. C., Hermans, C., Fally, S., Carleer, M., Colin, R., Mérienne, M.-F., Jenouvrier, A., and Coquart, B.: Highresolution Fourier transform measurement of the $\mathrm{NO}_{2}$ visible and near-infrared absorption cross-section: temperature and pressure effects, J. Geophys. Res., 107, 4348, doi:10.1029/2001JD000971, 2002.

Wendisch, M. and Brenguier, J.-L.: In situ trace gas measurements, in: Airborne Measurements for Environmental Research: Methods and Instruments, Wiley-VCH, Berlin, 611 pp., 2013.

Whalley, L. K., Edwards, P. M., Furneaux, K. L., Goddard, A., Ingham, T., Evans, M. J., Stone, D., Hopkins, J. R., Jones, C. E., Karunaharan, A., Lee, J. D., Lewis, A. C., Monks, P. S., Moller, S. J., and Heard, D. E.: Quantifying the magnitude of a missing hydroxyl radical source in a tropical rainforest, Atmos. Chem. Phys., 11, 7223-7233, doi:10.5194/acp-11-7223-2011, 2011. 


\section{Appendix A}

Table A1. Acronyms used in this paper.

\begin{tabular}{ll}
\hline Abbreviation & Meaning \\
\hline (e)CL & (effective) chain length \\
CIMS & chemical ionization mass spectrometry \\
CRDS & cavity ring-down spectroscopy \\
DUALER & dual channel chemical amplifier \\
ECDL & extended cavity diode laser \\
HALO & high altitude and long range research aircraft \\
LIF & laser induced fluorescence \\
MIESR & matrix isolation electron spin resonance \\
NICE-OHMS & noise immune cavity enhanced optical heterodyne molecular spectroscopy \\
OF-CEAS & optical feedback cavity enhanced absorption spectroscopy \\
OMO & oxidation mechanisms, observations in the extra-tropical free troposphere \\
PeRCA & peroxy radical chemical amplification \\
PeRCEAS & peroxy radical chemical enhancement and absorption spectroscopy \\
PMT & photomultiplier tube \\
PFA & perfluoralkoxy \\
PAN & peroxyacetyl nitrate \\
pptv, ppbv, ppmv & parts per trillion/billion/million of volume \\
roc & radius of curvature \\
sLpm & standard $\left(p_{\text {st }}=1013 \mathrm{hPa}, T_{\text {st }}=273.15 \mathrm{~K}\right)$ litres per minute \\
\hline
\end{tabular}

